\title{
Significance of haemodynamic variables in coronary care unit for prediction of survival after acute myocardial infarction
}

\author{
BRUCE H R WOLFFENBUTTEL, PIETER D VERDOUW, MICHAEL G SCHEFFER, HENNY \\ P A BOM, RONALD E BIJLEVELD, PAUL G HUGENHOLTZ
}

From the Department of Cardiovascular Research, Thoraxcenter, Erasmus University Rotterdam, Rotterdam, The Netherlands

SUMMARY In order to assess the value of haemodynamic monitoring in the coronary care unit for long term prognosis after recovery of an acute myocardial infarction, the records of two groups of consecutive patients were reviewed retrospectively. From 254 patients, 32 (13\%) died in the hospital and nine patients had to be excluded from subsequent follow-up for various reasons. Four year mortality among the 213 patients who were discharged from the hospital and could be followed up was $26 \%$. Of the haemodynamic variables measured on admission a high pulmonary capillary wedge pressure, exceeding $18 \mathrm{mmHg}$, and a low mixed venous oxygen saturation, less than $60 \%$, were not only associated with a high hospital but also with a high four year mortality, whereas a low systolic blood pressure (less than $100 \mathrm{mmHg}$ ), an important prognosticator during admission to hospital, was only of minor significance thereafter. A negative value on admission of a specific index $0.24 \times$ systolic blood pressure $(\mathrm{mmHg})-0.217 \times$ pulmonary capillary wedge pressure $(\mathrm{mmHg})+0.234 \times$ mixed venous oxygen saturation $(\%)-13.1$ developed for the prediction of short term survival was also associated with a much higher four year mortality than a positive value. Low cardiac index on admission could be correlated with high mortality during the first two years after discharge, whereas only $9 \%$ of patients with a higher cardiac index died. Haemodynamic monitoring in the coronary care unit is thus not only relevant for the immediate prognosis, but a high mortality risk during hospital stay persists for several years after discharge.

The search for reliable prognostic information to determine the short and long term outcome after acute myocardial infarction is still continuing. Previous investigations in our coronary care unit yielded an index, based on haemodynamic variables obtained at admission, which classifies patients with an acute myocardial infarction as having a high or a low hospital mortality risk. ${ }^{2}$ Hospital mortality proved to be lower than $5 \%$ in those patients in whom the admission value of the index $(0.024 \times$ systolic blood pressure $(\mathrm{mmHg})-0.217 \times$ pulmonary capillary wedge pressure $(\mathrm{mmHg})+0.234 \times$ mixed venous $0_{2}$-saturation (\%)-13.1) was positive and exceeded $50 \%$ when the index was negative. In this study we report on the results of a four year follow-up of these patients who

Accepted for publication 3 May 1983 recovered from their infarction and were discharged from the hospital.

Patients and methods

The data base for this study consisted of two groups of consecutive patients admitted to our coronary care unit with an acute myocardial infarction (WHO criteria) within 24 hours after the onset of symptoms. The first group consisted of 122 patients admitted in 1973, while the other group contained 132 patients admitted in 1977. The clinical data describing these groups and their treatment while in hospital and other relevant data have been described in detail in earlier communications. ${ }^{12}$ Both groups were very similar in age, sex, treatment, and mortality. All patients had a Swan Ganz balloon-tipped catheter inserted into the pulmonary artery immediately after admission to allow 
Table 1 Details of 245 patients with an acute myocardial infarction

\begin{tabular}{ccll}
\hline & & \multicolumn{2}{l}{ Four year follow-up } \\
\cline { 3 - 4 } & $\begin{array}{l}\text { Hospital deaths } \\
\mathrm{n}=32\end{array}$ & $\begin{array}{l}\text { Non-survivors } \\
\mathrm{n}=55\end{array}$ & $\begin{array}{l}\text { Survivors } \\
\mathrm{n}=158\end{array}$ \\
\hline $\begin{array}{l}\text { Sex } \\
\text { Male }\end{array}$ & 9 & 10 & 25 \\
$\begin{array}{c}\text { Female } \\
\text { Age (y) }\end{array}$ & 23 & 45 & 133 \\
$\begin{array}{c}\text { Range } \\
\text { Median }\end{array}$ & $31-81$ & $40-80$ & $28-75$ \\
\hline
\end{tabular}

measurements of pulmonary artery pressures and mixed venous oxygen saturation. In the second group of patients it was also possible to perform repeated cardiac output measurements with this catheter by means of the thermodilution technique. Hospital death was defined as mortality occurring within four weeks after admission. Thirty-two of the 254 patients died in the hospital. In 1981, the overall mortality among the 222 survivors was obtained by inspection of our own outpatient files, or from information obtained from the population registration office of the city of Rotterdam and surroundings. This provided us with an eight year follow-up from the first (1973) group and a four year follow-up from the second (1977) group. Three patients had to be excluded, because no follow-up could be obtained. From six other patients, who entered twice because of reinfarction, the follow-up started at discharge after their first admission. Of the remaining 213 patients (Table 1), $158(74 \%)$ were survivors after four years, while 55 (26\%) had died (non-survivors). Except in three cases (one patient died of a stroke and two died from malignant diseases) all causes of death were recorded to have been of cardiac origin. Fifteen patients died suddenly (instantaneously or within half an hour after onset of complaints), 25 died as a result of a new ischaemic event, and 12 patients died from other car-

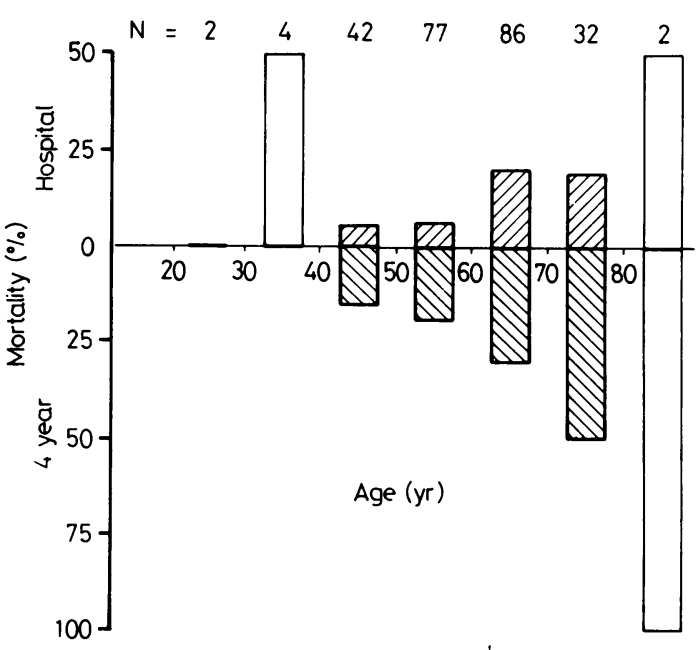

Fig. 1 Effect of age on hospital death and four year mortality after discharge in the various age classes. Notice that hospital as well as four year mortality is higher for patients older than 60 years than for those younger than 60 years.

diac causes (chronic congestive heart failure). Necropsies were not available in most of these deaths. The most advantageous cut-off points in predicting survival or mortality were determined for age, individual and combined haemodynamic variables, using operating characteristic curves, ${ }^{34}$ in which sensitivity of a particular variable in predicting mortality was plotted against specificity (see Appendix).

The significances of the cut-off points were determined using contingency tables. Student's t test was used to compare survivors, four year non-survivors, and hospital deaths. $P$ values less than 0.05 were considered to be statistically significant.

\section{Results}

In our previous studies we showed that age was not a

Table 2 Admission values of haemodynamic variables in coronary care unit in 245 patients with acute myocardial infarction

\begin{tabular}{|c|c|c|c|c|c|c|}
\hline & \multicolumn{3}{|l|}{ Four year follow-up } & \multicolumn{3}{|l|}{$p$ values } \\
\hline & $\underset{(n=32)}{\text { Hospital deaths }(A)}$ & $\begin{array}{l}\text { Non-survioors }(B) \\
(n=55)\end{array}$ & $\begin{array}{l}\text { Survivors }(C) \\
(n=158)\end{array}$ & $A \cup B$ & $A v C$ & $B v C$ \\
\hline $\begin{array}{l}\text { HR (beats/min) } \\
\text { SBP (mmHg) } \\
\text { DBP (mmHg) } \\
\text { PCW (mmHg) } \\
\text { MVO }_{2} \text {-sat (\%) }\end{array}$ & $\begin{array}{r}97 \cdot 3 \pm 20.4 \\
103 \cdot 3 \pm 35 \cdot 7 \\
67 \cdot 6 \pm 25 \cdot 3 \\
22.1 \pm 6 \cdot 4 \\
54 \cdot 3 \pm 12 \cdot 0\end{array}$ & $\begin{array}{r}83 \cdot 3 \pm 19.2 \\
131 \cdot 1 \pm 26.7 \\
85 \cdot 7 \pm 17 \cdot 8 \\
15.4 \pm 6.6 \\
65 \cdot 1 \pm 7 \cdot 7\end{array}$ & $\begin{array}{r}79.5 \pm 16.7 \\
138 \cdot 1 \pm 25.9 \\
89.8 \pm 17 \cdot 0 \\
13.3 \pm 5.3 \\
68 \cdot 8 \pm 6.0\end{array}$ & $\begin{array}{l}0.005 \\
0.001 \\
0.001 \\
0.001 \\
0.001\end{array}$ & $\begin{array}{l}0.001 \\
0.001 \\
0.001 \\
0.001 \\
0.001\end{array}$ & $\begin{array}{l}\text { NS } \\
\text { NS } \\
\text { NS } \\
0.02 \\
0.001\end{array}$ \\
\hline $\begin{array}{l}\text { PI } \\
\text { CI }\left(1 / \text { min per } m^{2}\right)\end{array}$ & $\begin{aligned} &-2.7 \pm 3.9 \\
& 1.7 \pm 0.4(n=16)\end{aligned}$ & $\begin{array}{l}1.9 \pm 2.9 \\
2.3 \pm 0.5(n=29)\end{array}$ & $\begin{array}{l}3.5 \pm 2.5 \\
2.6 \pm 0.9(n=83)\end{array}$ & $\begin{array}{l}0.001 \\
0.001\end{array}$ & $\begin{array}{l}0.001 \\
0.001\end{array}$ & $\begin{array}{l}0.001 \\
0.02\end{array}$ \\
\hline
\end{tabular}

HR, heart rate; SBP and DBP, systolic and diastolic arterial blood pressure; PCW, pulmonary capillary wedge pressure; $M \mathrm{O}_{\text {-sat, }}$ mixed venous oxygen saturation (\%); PI, 0.024 SBP- $0.217 \mathrm{PCW}+0.234 \mathrm{MVO}_{2}$-sat-13.1; CI, cardiac index. Cardiac index was determined only in the 132 patients admitted in 1977 . Data are presented as mean \pm SD. 


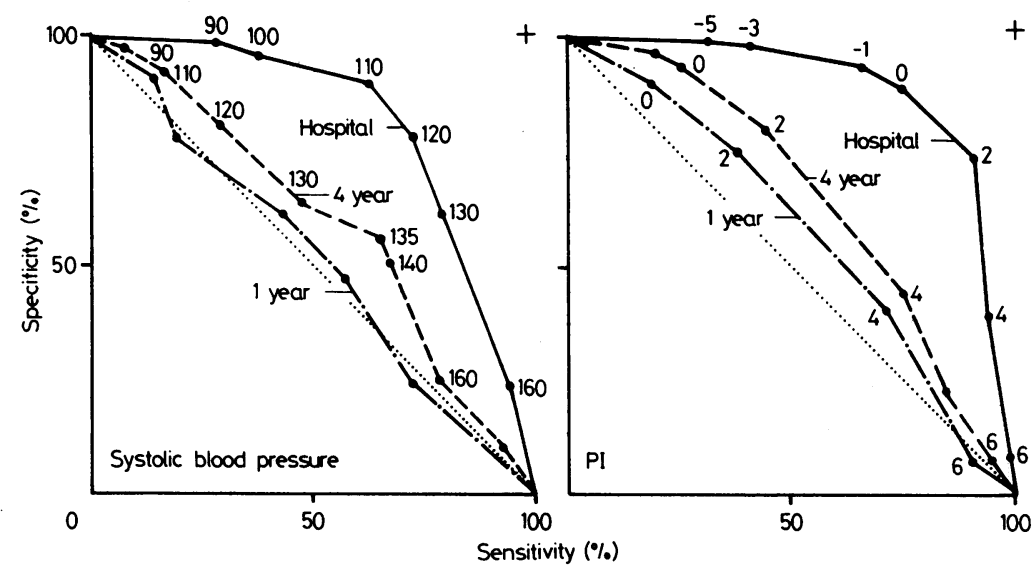

Fig. 2 Operating characteristic curves for systolic blood pressure $(S B P)$, and the index $P I=0.024 \times S B P-0.217 \times P C W+0.234 \times M V O_{2}$-sat-13.1. Observe that both are useful in the prediction of hospital mortality, but are of limited value for the determination of long term prognosis.

+characterises the optimal point in prediction of mortality with $100 \%$ sensitivity and $100 \%$ specificity.

major discriminator in the prediction of hospital survival and mortality. Similarly, age was not a major factor for the prediction of survival in the first four years after infarction, though both hospital and four year mortality increased slightly with age. Four year mortality was $36 \%$ (34 out of 95 ) in the group of patients older than 60 years, compared with $18 \%$ (21 out of 118) in the group of patients younger than 60 years $(p<0.02$, Fig. 1). On the other hand, all individual haemodynamic variables showed significant differences between those patients who died in the hospital and the initial survivors (Table 2). As described in the earlier communications, ${ }^{12}$ combination of the individual variables provided a better discrimination between the short term mortality and survival. The operating characteristic curves for systolic blood pressure and the combined index are shown in Fig. 2. For the prognosis of one year mortality after discharge, haemodynamic monitoring appears to be of much less value than for the prediction of hospital survival, but both indices have a tendency to increase their value for the prediction of four

Table 3 Threshold values of haemodymamic variables predicting four year survival afier recovery of myocardial infarction

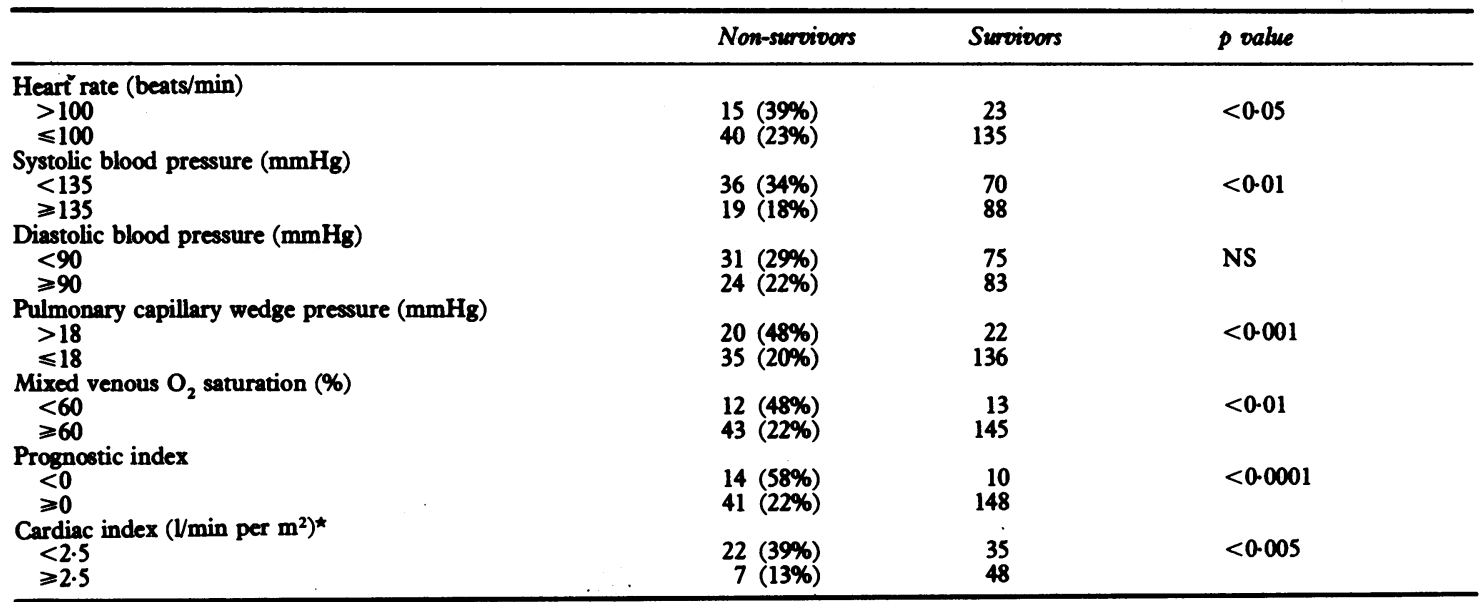

^Cardiac index was determined only in the patients admitted to coronary care unit in 1977 (112 hospital survivors).

PI, 0.024 SBP -0.217 PCW +0.234 $\mathrm{MVO}_{2}$-sat-13.1. 


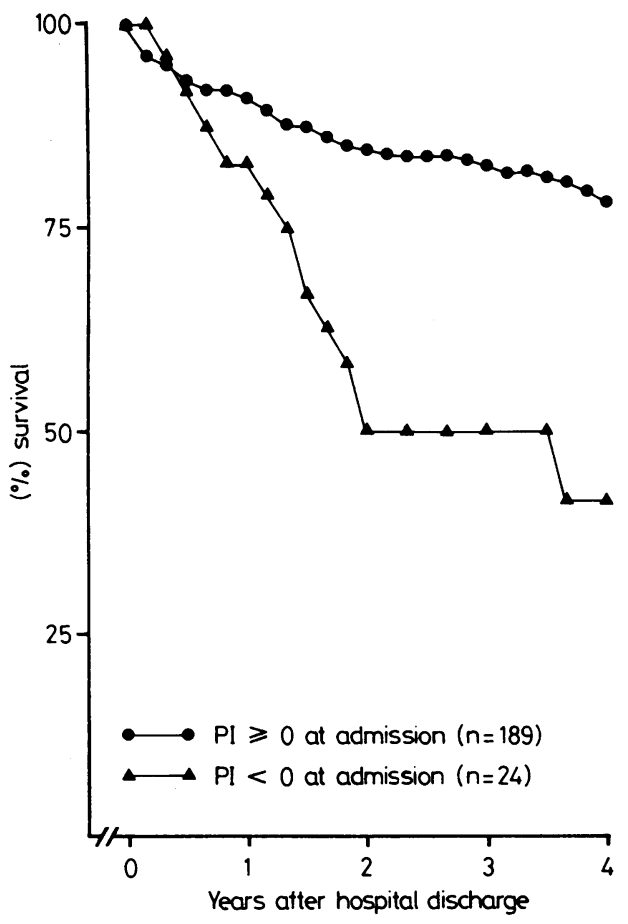

Fig. 3 Four year survival of patients who were discharged from the hospital after admission for acute myocardial infarction. Notice that a poor haemodynamic function upon admission (that is negative PI) also carries a poor long term prognosis.

year mortality. The same holds true for the other haemodynamic variables (not shown). The most advantageous cut-off points for long term survival are presented in Table 3. Four year mortality was more than twice as high among patients with a pulmonary capillary wedge pressure more than $18 \mathrm{mmHg}$ or a mixed venous oxygen saturation less than $60 \%$ at admission than among those with a pulmonary capillary wedge pressure of $18 \mathrm{mmHg}$ or less or a mixed venous oxygen saturation of $60 \%$ or more. Again, the combination of the individual variables into the prognostic index provided a slightly better discrimination (Table 3) as mortality in the patients with a negative index was nearly three times as high as in those with a positive index (58 vs $22 \%, \mathrm{p}<0.0001$ ). The much larger late mortality among patients with a negative index at admission is especially noteworthy in the first two years, as it is $50 \%$ for patients in this group against only $15 \%$ among those with a positive index (Fig. 3). Cardiac index, measured only in the 132 patients of the second group, showed a similar pattern to mixed venous oxygen saturation and prognostic index. Mortality among the patients with a cardiac index less than $2.5 \mathrm{l} / \mathrm{min}$ per $\mathrm{m}^{2}$ (22 our of 57) was three times higher than among those with a cardiac index of $2.5 \mathrm{l} / \mathrm{min}$ per $\mathrm{m}^{2}$ or more (seven out of 55) on admission (39 vs $13 \%, p<0.005$ ). A similar difference could already be seen in the first two years, since $30 \%$ (17 out of 57) of the patients with a cardiac index less than $2.51 \mathrm{l} / \mathrm{min}$ per $\mathrm{m}^{2}$ died in that period, against only $9 \%$ (five out of 55 ) of patients with a cardiac of $2.4 \mathrm{l} / \mathrm{min}$ per $\mathrm{m}^{2}$ or more.

\section{Discussion}

It has been suggested that the intensive therapy used. in the coronary care unit nowadays should virtually eliminate all deaths resulting primarily from rhythm disturbances and reduce hospital mortality in patients with left heart failure and cardiac shock. Others have pointed out that myocardial damage in patients with left heart failure and shock might be so severe that their long term prognosis still remains unfavourable and that intensive care only postpones the time of death by a short period. Chatterjee et al. ${ }^{5}$ have indeed shown that vasodilator therapy reduced hospital mortality in patients with severe pump failure, but that the cumulative mortality after two years was not different from similar groups of patients treated by other means. Those data therefore confirm that such treatment has led to only a minor delay in the demise of these patients. It seemed appropriate, therefore, to investigate whether these high risk patients could be classified as soon as possible during their stay in hospital by objective measurements and then to follow their course. This would facilitate considerably the selection of candidates for aggressive treatment and the evaluation of new therapeutical approaches.

Prognosis of patients who have recovered from an acute myocardial infarction has usually been obtained from non-invasive measurements at admission or from data collected during the course of their stay in hospital. ${ }^{6-13}$ The data in this study describe the usefulness for long term prognosis of an invasive index, originally developed for classification of patients with high or low mortality risks during admission. ${ }^{1}$ One and four year mortalities of the patients who recovered from their myocardial infarction were respectively, $10 \%$ and $26 \%$, similar to those published by other investigators. ${ }^{6710}$ Our study also showed that mortality during the first two years among the patients with a negative value for the prognostic index was more than three times as high as that among patients with a positive index (50 vs $15 \%$, respectively). A high pulmonary capillary wedge pressure $(>18 \mathrm{mmHg}$ ) and a low mixed venous oxygen saturation $(<60 \%)$ proved to be particularly associated with an increased risk of late death (Table 2). Systolic blood pressure, though a valuable measure for the determination of short term survival, was only of 
limited value for the prediction of long term survival. A similar finding was reported by Norris et al. ${ }^{6}$ in their prediction of three year survival. With the use of operating characteristic curves it could be shown that the individual haemodynamic variables failed to predict mortality in the first year after discharge, but partially regained their prognostic value in the three years thereafter. This finding seems to be in disagreement with reports by other authors. Here the mode and mechanism of death, however, have to be taken into account.

In our patient population, seven of the 21 deaths during the first year were in fact "sudden deaths", probably from ventricular fibrillation. All but one had only a small infarction during their initial stay in hospital, with good to excellent haemodynamic variables. These deaths could therefore not have been predicted on grounds of haemodynamic variables, nor did peak enzyme levels of these patients (CK, HBDH) contribute much, since they were relatively low in the acute phase of the infarction.

Heart size, lung fields, and other clinical signs of left heart failure have all been shown to increase mortality risk. ${ }^{6811}$ They may all be considered to be noninvasive reflections of a high pulmonary capillary wedge pressure. The value of left ventricular filling pressure for the prediction of long term prognosis had earlier been pointed out by Rogers et al. ${ }^{12}$ Pulmonary artery oxygen content (mixed venous oxygen saturation) reflects myocardial pump function, provided that arterial oxygen content and total body oxygen consumption are not subject to large alterations. Therefore, the exact quantification of these two variables seems to be preferable. Mixed venous oxygen saturation showed, however, only a weak correlation with cardiac index $(r=0.60 ; n=128)$ when all patient data obtained at admission were pooled. Since arterial oxygen content was nearly always normal, this indicates that the total body oxygen consumption data differed greatly. Nevertheless, a cardiac index of less than $2.2 \mathrm{l} / \mathrm{min}$ per $\mathrm{m}^{2}$ was associated with a mixed venous oxygen saturation less than $60 \%$ in 23 out of 38 patients, which shows that a low mixed venous oxygen saturation usually implies poor pump function. Cardiac index at admission provided valuable information about long term prognosis in the subset of 132 patients in which it was measured. During the first two years after hospital discharge, a low cardiac index carried a high risk, as $30 \%$ of patients with a cardiac index less than $2.5 \mathrm{l} / \mathrm{min}$ per $\mathrm{m}^{2}$ died, against only $9 \%$ of patients with a cardiac index of $2.5 \mathrm{l} / \mathrm{min}$ per $\mathrm{m}^{2}$ or more. This finding is at variance with that reported by Rogers et al. ${ }^{12}$ who found, in a smaller group of patients, that cardiac index did not play a major role in the prediction of two year survival.

Long term prognosis not only depends on the amount of damaged muscle, but also on the nature of the obstructive disease in the arteries supplying still viable myocardium. Exercise testing shortly before hospital discharge may provide additional information about the ultimate outcome. Theroux et al. ${ }^{14}$ found that patients who developed a ST segment depression of at least $1 \mathrm{~mm}$ during submaximal treadmill exercise testing, carried a $27 \%$ one year mortality risk, compared with a $2 \%$ mortality among patients without ST depression. Other reports confirm the prognostic value of exercise testing, alone ${ }^{15}$ or in combination with radionuclide ventriculography. ${ }^{16} \mathrm{~A}$ major drawback of such studies is that a sizeable number of patients is excluded from exercising for various reasons, such as congestive heart failure, advanced age, clinical or radiological signs of pulmonary con-

Table 4 Calculation of operating characteristic curves

\begin{tabular}{|c|c|c|c|c|}
\hline \multirow[b]{2}{*}{ Systolic blood pressure } & \multicolumn{2}{|l|}{ Hospital } & \multirow[b]{2}{*}{ Sensitivity (\%) } & \multirow[b]{2}{*}{ Specificity (\% } \\
\hline & Mortality & Survival & & \\
\hline $\begin{array}{l}<90(\mathrm{mmHg}) \\
\geqslant 90 \\
<110 \\
\geqslant 110 \\
<160 \\
\geqslant 160\end{array}$ & $\begin{array}{r}9 \text { (=TP) } \\
23(=\text { FN }) \\
20 \\
12 \\
30 \\
2\end{array}$ & $\begin{array}{r}2 \text { (=FP) } \\
211 \text { (=TN) } \\
21 \\
192 \\
162 \\
51\end{array}$ & $\begin{array}{l}28 \\
63 \\
94\end{array}$ & $\begin{array}{l}99 \\
90 \\
24\end{array}$ \\
\hline
\end{tabular}

Defunitions
Sensitivity $(\%)=\frac{\mathrm{TP}}{\mathrm{TP}+\mathrm{FN}} \times 100$
Specificity $(\%)=\frac{\mathrm{TN}}{\mathrm{FP}+\mathrm{TN}} \times 100$

TP, true positive prediction of mortality; FN, false negative prediction of mortality; TN, true negative prediction of mortality; FP, false positive prediction of mortality. 
gestion or cardiac enlargement, or treatment with digitalis or propranolol. Since mortality among the excluded patients can be considerable, the real prognostic value of these tests is limited. The predictive significance of angiographic data has also been shown only for selected patients, ${ }^{17} 18$ but depressed left ventricular ejection fraction, the extent of diseased coronary vessels, and the occurrence of congestive heart failure while still in the coronary care unit have been found to be independent predictors of mortality.

We conclude from our study that haemodynamic measurements at admission provide valuable information about both the immediate and the long term prognosis of patients with an acute myocardial infarction, though differences can be encountered in predictive strength of these variables in terms of one and four year mortality. Further studies must be carried out to elaborate the distinct possibility that a combination of haemodynamic measurements with other important indicators such as those derived from exercise testing, arrhythmias, and biochemical information, will further enhance prediction of long term survival.

\section{Appendix}

We wish to illustrate the use of operating characteristic curves in predicting outcome after myocardial infarction with the following example. In our patient population we found that 11 patients had an admission systolic blood pressure $<90 \mathrm{mmHg}$, of whom nine died and two survived. Of the 234 patients with a systolic blood pressure $\geqslant 90 \mathrm{mmHg}, 23$ died and 211 survived (Table 4). The data for two other blood pressure levels are given in the same Table. With the aid of the definitions shown at the bottom of Table 4 we can now calculate the sensitivity and specificity in predicting mortality for each level of blood pressure. The resulting curve is shown in Fig. 2. Consider first the curve labelled hospital. An admission systolic blood pressure of $<90 \mathrm{mmHg}$ is highly specific for hospital death, but its sensitivity was poor, since most patients who died during hospital admission had a higher initial blood pressure. At the other end of the curve we find, not unexpectedly, that most patients who died had an initial blood pressure of $<160$ $\mathrm{mmHg}$. A high systolic blood pressure therefore appears to be a sensitive indicator, though it is almost totally non-specific and therefore not useful. Inspection of the whole curve shows that the point corresponding to a pressure of $110 \mathrm{mmHg}$ offers the best compromise between specificity and sensitivity. Clearly the closer the curve approaches the point + , the more powerful the predictor. Conversely, a curve which approximates to the dotted diagonal line is based on information which carries no prognostic value. This is more or less the case for the blood pressure curve at one year, but at four years the variable has regained some of its prognostic value with the point corresponding to a pressure of $135 \mathrm{mmHg}$ seeming to be the most useful cut-off point.

\section{References}

1 Verdouw PD, Hagemeijer F, Van Dorp WG, Van der Vorm A, Hugenholtz PG. Short-term survival after acute myocardial infarction predicted by hemodynamic parameters. Circulation 1975; 52: 413-9.

2 Wolffenbuttel BHR, Verdouw PD, Hugenholtz PG. Immediate and two year prognosis after acute myocardial infarction: prediction from non-invasive as well as invasive parameters in the same individuals. Eur Heart $\mathcal{f}$ 1981; 2: 375-87.

3 McNeil BJ, Keeler E, Adelstein SJ. Primer on certain elements of medical decision making. $N$ Engl f Med 1975; 293: 211-5.

4 Katz MA. A probability graph describing the predictive value of a highly sensitive diagnostic test. $N$ Engl $\mathcal{Y}$ Med 1974; 291: 1115-6.

5 Chatterjee K, Swan HJC, Kaushik VS, Jobin G, Magnusson P, Forrester JS. Effects of vasodilator therapy for severe pump failure in acute myocardial infarction on short-term and late prognosis. Circulation 1976; 53: 797-802.

6 Norris RM, Caughey DE, Mercer CJ, Scott PJ. Prognosis after myocardial infarction-six year follow-up. $\mathrm{Br}$ Heart f 1974; 36: 786-90.

7 Kitchin AH, Pocock SJ. Prognosis of patients with acute myocardial infarction admitted to a coronary care unit. II: Survival after hospital discharge. Br Heart $f$ 1977; 39: 1167-71.

8 Humphries JO. Survival after myocardial infarctionPrognosis and management. Mod Concepts Cardiovasc Dis 1977; 46: 51-6.

9 Bigger JT Jr, Heller CA, Wenger TL, Weld FM. Risk stratification after acute myocardial infarction. Am $\mathcal{F}$ Cardiol 1978; 42: 202-10.

10 Luria MH, Knoke JD, Wachs JS, Luria MA. Survival after recovery from acute myocardial infarction-two and five year prognostic indices. Am $\mathcal{F}$ Med 1979; 67: 7-14.

11 Henning $R$, Wedel $H$. The long-term prognosis after myocardial infarction: a five year follow-up study. Eur Heart f 1981; 2: 65-74.

12 Rogers WJ, Smith LR, Oberman A, Mantle JA, Russell RO, Rackley CE. Invasive measurements relating to long-term survival post-myocardial infarction [Abstract]. Circulation 1979; 59 \& 60 (suppl II):232.

13 Wilhelmsen L. Prognostic indices after acute myocardial infarction and secondary preventive measures. In: Report of WHO working group: The development of coronary care in the community. Brussel, 1979: annex IV, 30-5.

14 Theroux P, Waters DD, Halphen C, Debaisieux JC, Mizgala HF. Prognostic value of exercise testing soon after myocardial infarction. $N$ Engl $f$ Med 1979; 301: 341-5. 
15 Davidson DM, Debusk RF. Prognostic value of a single exercise test 3 weeks after uncomplicated myocardial infarction. Circulation 1980; 61: 236-42.

16 Corbett JR, Dehmer GJ, Lewis SE, et al. The prognostic value of submaximal exercise testing with radionuclide ventriculography before hospital discharge in patients with recent myocardial infarction. Circulation 1981; 64: 535-44.

17 Sanz G, Castañer A, Betriu A, et al. Determinants of prognosis in survivors of myocardial infarction: a prospective clinical angiographic study. $N$ Engl $\mathcal{F}$ Med 1982; 306: 1065-70.
18 Taylor GJ, Humphries JO, Mellits ED, et al. Predictors of clinical course, coronary anatomy and left ventricular function after recovery from acute myocardial infarction. Circulation 1980; 62: 960-70.

Requests for reprints to Dr P D Verdouw, Department of Cardiovascular Research, Thoraxcenter, Erasmus University Rotterdam, PO Box 1738, 3000 DR Rotterdam, The Netherlands. 